\title{
Biosynthesis and characterization of silver nanoparticles induced by fungal proteins and its application in different biological activities
}

\author{
Abdelmageed M. Othman ${ }^{1 *}$ (D, Maysa A. Elsayed ${ }^{1}$, Naser G. Al-Balakocy², Mohamed M. Hassan ${ }^{1}$ and Ali M. Elshafei ${ }^{1}$
}

\begin{abstract}
Background: The present study aims to apply an efficient eco-friendly and inexpensive process for green synthesis of silver nanoparticles (AgNPs) through the mediation of fungal proteins from Aspergillus fumigatus DSM819, characterization, and its application as antimicrobial finishing agent in textile fabrics against some infectious microorganisms.

Results: Optimum conditions for AgNP biosynthesis could be achieved by means of using $60 \%(\mathrm{v} / \mathrm{v})$ of cell-free filtrate (CFF) and $1.5 \mathrm{mM}$ of $\mathrm{AgNO}_{3}$ at pH 10.0 after 90 min. The obtained AgNPs were of spherical shape with 90\% of distribution below than $84.4 \mathrm{~nm}$. The biosynthesized AgNPs exerted an antimicrobial activity against the studied pathogenic microorganisms (E. coli, B. mycoides, and C. albicans). In addition, IC $C_{50}$ values against in vitro tumor cell lines were found to be 31.1, 45.4, 40.9, and $33.5 \mathrm{\mu g} / \mathrm{ml}$ for HCT116, A549, MCF7, and PC3, respectively. Even with a very low concentration (0.25\%), the treated PET/C fabrics by AgNPs exerted an antimicrobial activity against E. coli, B. mycoides, and C. albicans to give inhibition zone diameter of 15, 15, and $16 \mathrm{~mm}$, respectively.

Conclusions: The green biosynthesis approach applied in this study is a non-toxic alternative to the traditional chemical and physical methods, and would be appropriate for biological large-scale production and prospective treatments.
\end{abstract}

Keywords: Silver nanoparticles, Aspergillus fumigatus, Biosynthesis, Characterization, Antimicrobial, Antitumor

\section{Background}

The advantages of using microbiological synthesis of silver nanoparticles (AgNPs) over chemical method has gained more importance during the last few years due to its higher and faster production and being lower cost and eco-friendly [33]. Generally, the synthesis of nanoparticles (NPs) received particular attention by the scientific community due to their unique properties and for their technological applications which reflect positively in improving many sectors of economy including pharmaceutics, cosmetics, industry, energy, and agriculture [22].

\footnotetext{
* Correspondence: othmanam_nrc@yahoo.com; am.othman@nrc.sci.eg ${ }^{1}$ Microbial Chemistry Department, Genetic Engineering and Biotechnology Research Division, National Research Centre, 33 El Bohouth St., Dokki, Giza 12622, Egypt

Full list of author information is available at the end of the article
}

Metal nanoparticles (NPs) are very interesting to scientists as they bridge the gap between the bulk and atomic structures due to their physicochemical properties such as high surface area, precise pore size, and high reactivity [31]. Among the noble metal, silver plays a major role in medicine as it has been proven that silver was used for preventing bacterial infections and also exhibits wound healing activity. Investigations on silver nanoparticles (AgNPs) and their colloidal form exhibit catalytic and antibacterial properties, high conductivity, and chemical stability [29].

AgNPs can be prepared by various methods such as biological, physical, chemical, and other electrochemical, photochemical, sonolytic, and radiolytic methods [17]. Biological methods were found to be the most proper technique for the preparation of AgNPs, as NPs produced 
have a longer shelf life and stability as natural capping takes place. The green biosynthesis of NPs has a longer shelf life, cost effective and simple downstream processing, and effective purification methods. Plant extracts, bacteria, and fungi are the main sources involved in the biosynthesis of AgNPs [3].

Other sources for AgNP synthesis using biological materials such as honey [27], milk [12], coconut water [8], and egg white [14] were reported. Otunola and Afolayan [25] reported the synthesis, characterization, and biological properties of silver nanoparticles (AgNPs) using the extract from garlic, ginger and cayenne pepper (1:1: $1 ; \mathrm{w} / \mathrm{w} / \mathrm{w})$, and silver nitrate solution. Different fungi were able to effectively synthesize AgNPs. Mukherjee et al. [20] reported that Trichoderma asperellum synthesizes silver nanoparticles in the range of $13-18 \mathrm{~nm}$ when subjected to $\mathrm{AgNO}_{3}$ solution. Patil [26], Mukherjee et al. [19], and Kathiresan et al. [10] reported the formation of AgNPs using Fusarium semitectum, Verticillium sp., and Penicillium fellutanum, respectively. An efficient ecofriendly synthesis of silver nanoparticles (AgNPs) using aqueous culture filtrate of Pestalotiopsis microspora has been reported. The analysis of UV-visible confirmed AgNP formation at absorption peak at $435 \mathrm{~nm}$ [21].

In the present work, silver nanoparticles (AgNPs) synthesized by a microbiological method using Aspergillus fumigatus were applied in textile fabrics and tested as antimicrobial finishing agent against some infectious microorganisms as well as an antitumor agent using different tumor cell lines.

\section{Methods}

\section{Chemicals}

Nutrient agar medium (70148 nutrient agar) was provided by Fluka, Spain. Glucose was purchased from Koch-Light Lab., England. Silver nitrate was provided by Sisco Research lab, India. Potassium chloride was obtained from Merck, Germany. Agar-Agar was obtained from Fluka, France. Polyester/cotton blend (PET/C 50/ 50) fabrics in form of filament woven fabric cloth made from filament yarns was kindly supplied by Misr Polyester Co., Kafr EL-Dwar, Egypt. Acid cellulase enzyme (Cellusoft ${ }^{\circ} \mathrm{L}$ ) used for fabric pretreatment was obtained from Novo Nordisk, Denmark.

\section{Microorganisms}

Aspergillus fumigatus DSM819 was cultured and stored on modified Czapek-Dox's solid medium slants and refreshed before use. For the purpose of antimicrobial determinations, Escherichia coli, Bacillus mycoides, and Candida albicans were applied as representative microorganisms of Gram-negative bacteria, Gram-positive bacteria, and non-filamentous fungi. They were maintained on nutrient agar medium with the following composition $(\mathrm{g} / \mathrm{l})$ : peptone, 3 ; yeast extract, 1.5 ; meat extract, 1.5; glucose, $0.5 ; \mathrm{NaCl}, 0.25$; and agar, 20.0 at $\mathrm{pH}$ 7.0. All microbial cultures applied in this study were obtained from the culture collection of Microbial Chemistry Dept., NRC, Egypt.

\section{Preparation of cell-free filtrate and AgNP biosynthesis} A. fumigatus DSM819 was cultivated in $250 \mathrm{ml}$ Erlenmeyer conical flasks which contained $50 \mathrm{ml}$ of the modified Czapek-Dox's liquid medium (g/l): $\mathrm{NaNO}_{3}, 2$; $\mathrm{KH}_{2} \mathrm{PO}_{4}, 1 ; \mathrm{MgSO}_{4 .} 7 \mathrm{H}_{2} \mathrm{O}, 0.5 ; \mathrm{KCl}, 0.5$; and glucose, 20 for 6 days at $28^{\circ} \mathrm{C}$ under static conditions. After that, the culture was filtered via Whatman No. 1 filter paper and the resulted supernatant (cell-free filtrate; CFF) was applied for the mediation of AgNP biosynthesis. The obtained CFF was applied in various reaction mixtures containing silver nitrate aqueous solution $(1 \mathrm{mM})$ as silver source for AgNP biosynthesis process. Then, the mixtures were incubated in the dark (to avoid the photoactivation of silver nitrate) at $30^{\circ} \mathrm{C}$ and continues shake at $100 \mathrm{rpm}$. After incubation, the absorbance of the characteristic reddish brown color of the biosynthesized AgNPs was scanned using UV-visible spectrophotometer (Cary 100 UV-Vis; Agilent Technologies, Germany). Cell-free filtrates as well as silver nitrate solution $(1 \mathrm{mM})$ were used as controls.

\section{Optimization of AgNP biosynthesis}

The CFF obtained from A. fumigatus DSM819 culturing was added at different concentrations in ratios between 10 and $60 \%(\mathrm{v} / \mathrm{v})$, which means adding CFF volumes between 0.5 and $3.0 \mathrm{ml}$ to a total reaction mixture of $5.0 \mathrm{ml}$, while keeping the $\mathrm{AgNO}_{3}$ concentration at a level of $1.0 \mathrm{mM}$. The $\mathrm{pH}$ value effect was studied through preparing different reaction mixtures adjusted at $\mathrm{pH}$ values ranging between 9.0 and 11. The effect of reaction time on the AgNP biosynthesis process was evaluated by incubating the reaction mixtures at optimum conditions for 10, 20, $30,45,60,90$, and $120 \mathrm{~min}$. The effect of silver ions on the biosynthesis of AgNPs by A. fumigatus DSM819 was determined by varying the $\mathrm{AgNO}_{3}$ concentration to range from 0.5 to $1.5 \mathrm{mM}$. All experiments were carried out in triplicates, and the average data was presented.

\section{Characterization of the biosynthesized AgNPs}

The UV-visible spectra of AgNPs were recorded as a function of wavelength using UV/vis spectrophotometer (Cary 100 UV-Vis; Agilent Technologies, Germany) operated at data interval of $1.0 \mathrm{~nm}$. The AgNP solution was centrifuged for $20 \mathrm{~min}$ at $10000 \mathrm{rpm}$ and was drop coated on a carbon-coated copper grid and dried to be applied for studying both the scanning electron microscopic (SEM) and elemental analysis of the biosynthesized AgNPs using scanning electron microscope (SEM-Quanta 
FEG250) operated at an accelerating voltage of $20 \mathrm{kV}$ and coupled with energy dispersive X-ray analysis (EDAX) for compositional analysis and the conformation of presence of elemental silver.

The shape and size of AgNPs were determined by transmitting electron microscope (TEM). For TEM, a drop of aqueous AgNP sample was loaded on a carboncoated copper grid, and it was allowed to dry at room temperature; the micrographs were obtained using TEM (JEOL JEM-1230) at $160 \mathrm{kV}$. Particle size was measured on a dynamic light scattering (DLS) instrument (PSS, Santa Barbara, CA, USA), using the 632-nm line of a $\mathrm{HeNe}$ laser as the incident light with angel $90^{\circ}$.

For Fourier transform infrared (FTIR) spectroscopy measurements, reaction mixtures containing $\mathrm{AgNO}_{3}$ at a concentration of $1.5 \mathrm{mM}$ and A. fumigatus DSM819 CFF were prepared and incubated for $90 \mathrm{~min}$ at $\mathrm{pH} 10$ to form AgNPs, then centrifuged at 10,000 rpm for 15 min and re-dispersed in sterile distilled water. The process of centrifugation and re-dispersion was repeated four times to ensure good separation of the AgNPs from other contaminants. The obtained pellets were then dried, and the powders were subjected to FTIR spectroscopy measurement. These measurements were carried out on a JASCO FTIR (Japan) instrument in the diffuse reflectance mode at a resolution of 4 $\mathrm{cm}^{-1}$ in $\mathrm{KBr}$ pellets.

\section{Cytotoxic effect on human cell lines}

Cell viability was assessed by the mitochondrialdependent reduction of yellow MTT (3-(4,5-dimethylthiazol-2-yl)-2,5-diphenyl tetrazolium bromide) to purple formazan [18] in a sterile area using a Laminar flow cabinet biosafety class II level (Baker, SG403INT, Sanford, ME, USA). Cells (as a gift from Dr. Stig Linder, Karolinska institutet, Solna, Sweden) were suspended in RPMI 1640 medium, $1 \%$ antibiotic-antimycotic mixture $(10,000 \mathrm{U} / \mathrm{ml}$ potassium penicillin, $10,000 \mu \mathrm{g} / \mathrm{ml}$ streptomycin sulfate, and $25 \mu \mathrm{g} / \mathrm{ml}$ amphotericin B), and 1\% L-glutamine at $37^{\circ} \mathrm{C}$ under $5 \% \mathrm{CO}_{2}$. Cells were batch cultured for 10 days, then seeded at concentration of $10 \times 10^{3}$ cells/well in fresh complete growth medium in 96-well microtiter plastic plates at $37^{\circ} \mathrm{C}$ for $24 \mathrm{~h}$ under $5 \% \mathrm{CO}_{2}$ using a waterjacketed carbon dioxide incubator (Sheldon, TC2323, Cornelius, OR, USA). Media was aspirated, fresh medium (without serum) was added, and cells were incubated either alone (negative control) or with different concentrations of sample to give a final concentration $(54.0,27.0$, $13.5,6.75,3.37,1.68,0.84$, and $0.40 \mu \mathrm{g} / \mathrm{ml})$. After $48 \mathrm{~h}$ of incubation, medium was aspirated, and $40 \mu \mathrm{l}$ MTT salt $(2.5 \mu \mathrm{g} / \mathrm{ml})$ was added to each well and incubated for further $4 \mathrm{~h}$ at $37{ }^{\circ} \mathrm{C}$ under $5 \% \mathrm{CO}_{2}$. To stop the reaction and dissolving the formed crystals, $200 \mu \mathrm{l}$ of $10 \%$ sodium dodecyl sulfate (SDS) in deionized water was added to each well and incubated overnight at $37^{\circ} \mathrm{C}$. A positive control was used as a known cytotoxic natural agent who gives $100 \%$ lethality under the same conditions. The absorbance was measured using a microplate multi-well reader (BioRad Laboratories Inc., model 3350, Hercules, CA, USA) at $595 \mathrm{~nm}$ and a reference wavelength of $620 \mathrm{~nm}$. A statistical significance was tested between samples and negative control (cells with vehicle) using independent $t$ test by SPSS 11 program. DMSO is the vehicle used for dissolution with final concentration on the cells which was less than $0.2 \%$. The percentage of change in viability was calculated according to the formula: ((Reading of extract/ Reading of negative control) -1$) \times 100$. A probit analysis was carried for $\mathrm{IC}_{50}$ and $\mathrm{IC}_{90}$ determination using SPSS 11 program.

\section{Pretreatment of PET/C fabrics by cellulase}

Using a high-temperature high-pressure laboratory dyeing machine, cellulase (3\%) was placed in stainlesssteel bowls, then the fabrics were immersed in the solutions $(\mathrm{pH} 4.5)$, and the sealed bowls were rotated in a closed bath containing ethylene glycol at $45^{\circ} \mathrm{C}$. The material to liquor ratio was 1:15. The bath temperature increased at a rate of $5{ }^{\circ} \mathrm{C} / \mathrm{min}$, and after $40 \mathrm{~min}$, the enzymatic treatment was then terminated by raising the $\mathrm{pH}$ to 10 by using $\mathrm{Na}_{2} \mathrm{CO}_{3}$. The fabric samples were removed from the bath, rinsed repeatedly with distilled hot and cold water, and then allowed to dry in the open air.

\section{PET/C fabric treatment by the biosynthesized AgNPs}

The activated PET/C blend fabric by cellulase and un-hydrolyzed fabrics (blank without enzymatic treatment) were immersed in the biosynthesized AgNP dispersion, and then, the samples were squeezed to a pickup of $60 \%$ (wt/wt) of the solution, dried in air at $22^{\circ} \mathrm{C}$ for $24 \mathrm{~h}$, and finally cured in an oven at $140{ }^{\circ} \mathrm{C}$ for $10 \mathrm{~min}$. In order to evaluate the AgNP adhesion to the PET/C blend fabrics, the treated fabrics were washed five times according to a standard method AATCC Test Method (61-1989). The chemical structure was determined using FTIR spectrometer (model NEXUS 670, NICOLET, USA) in spectral range from 4000 to $400 \mathrm{~cm}^{-1}$.

\section{Assessment of antimicrobial activity}

For the assessment of AgNP antimicrobial activity, agar diffusion method was applied. The microbial strains were grown (seeding inoculation technique using $100 \mu \mathrm{l}$ of re-suspended overnight culture at $37^{\circ} \mathrm{C}\left(1 \times 10^{7}\right.$ $\mathrm{CFU} / 100 \mu \mathrm{l}))$ at $37^{\circ} \mathrm{C}$ on nutrient agar medium (70148 nutrient agar, Fluka, Spain) with the subsequent composition $(\mathrm{g} / \mathrm{l})$ : peptone, $5.0 ; \mathrm{NaCl}, 5.0$; yeast extract, 2.0 ; meat extract, 1.0; and agar 15.0 (pH 7.0). AgNP samples 
(108 $\mu \mathrm{g} / \mathrm{ml})$ obtained from the reaction of $A$. fumigatus DSM819 CFF and $\mathrm{AgNO}_{3}$ at different $\mathrm{pH}$ values were applied in a volume of $250 \mu \mathrm{l}$ into the pre-made holes in Petri dishes of the previously mentioned nutrient agar medium, whereas in case of PET/C fabrics treated by the biosynthesized AgNPs, circular discs of $12 \mathrm{~mm}$ from the treated fabrics were applied. Culture plates were left overnight at $4{ }^{\circ} \mathrm{C}$, and then, plates were incubated for $7 \mathrm{~h}$ at $37^{\circ} \mathrm{C}$. The developed inhibition zones were measured based on AATCC test method [7].

\section{Results}

\section{Biosynthesized AgNP UV-visible spectroscopy}

The UV-visible spectroscopy results using A. fumigatus DSM819 filtrate indicate the ability of $A$. fumigatus DSM819 to form AgNPs extracellulary through reduction of $\mathrm{Ag}^{+}$to form the AgNPs. Figure 1 shows the UV-vis spectroscopy scan of AgNP formation, and this peak is due to the change of reaction mixture color to reddish brown as a result of AgNP formation and SPR excitation. The distinct and typical SPR band for AgNPs was obtained in the region of $410 \mathrm{~nm}$ as a result of AgNP formation, in comparison to controls using CFF or silver nitrate solution separately, where there is no reddish brown color development and subsequently no typical SPR band for AgNPs, demonstrating the absence of abiotic reduction of silver nitrate.

\section{Optimization of AgNP biosynthesis} Effect of CFF ratio on AgNP biosynthesis

Different reaction mixtures in a total volume of $5.0 \mathrm{ml}$ including silver nitrate $(1 \mathrm{mM})$ and diverse ratios from CFF of $A$. fumigatus DSM819 ranging between 10 and $60 \%(\mathrm{v} / \mathrm{v})$ were tested. Results obtained indicate that the formation of AgNPs is directly proportional to the ratio of A. fumigatus DSM819 CFF, with maximum ability to biosynthesize AgNPs at ratio of $60 \%(\mathrm{v} / \mathrm{v})$. The ability of A. fumigatus DSM819 CFF to form AgNPs is gradually decreased by the decreasing of CFF ratio to give its lowest activity at a ratio of $10 \%(\mathrm{v} / \mathrm{v})$ which were declared by the SPR scanning peaks that are illustrated in Fig. 2a.

\section{Effect of $\mathrm{pH}$ value on AgNP formation}

The results obtained demonstrate the influencing effect of $\mathrm{pH}$ value on the biosynthesis of AgNPs by mediation of $A$. fumigatus DSM819 CFF. The optimum $\mathrm{pH}$ value for AgNP formation (the highest SPR peak intensity) was recorded at $\mathrm{pH} 10.0$ after investigating different reaction mixtures adjusted at different $\mathrm{pH}$ values (Fig. $2 \mathrm{~b}$ ). It is worthy to mention that the capability of the produced enzyme and protein as reducing and stabilizing agents appeared in alkaline medium, and when the reaction was performed at $\mathrm{pH}$ values lower than 9.0, no SPR peak was obtained. While, the adjustment of reaction mixture $\mathrm{pH}$ value to be higher than 11.0, an immediate precipitate of silver was obtained that impede the

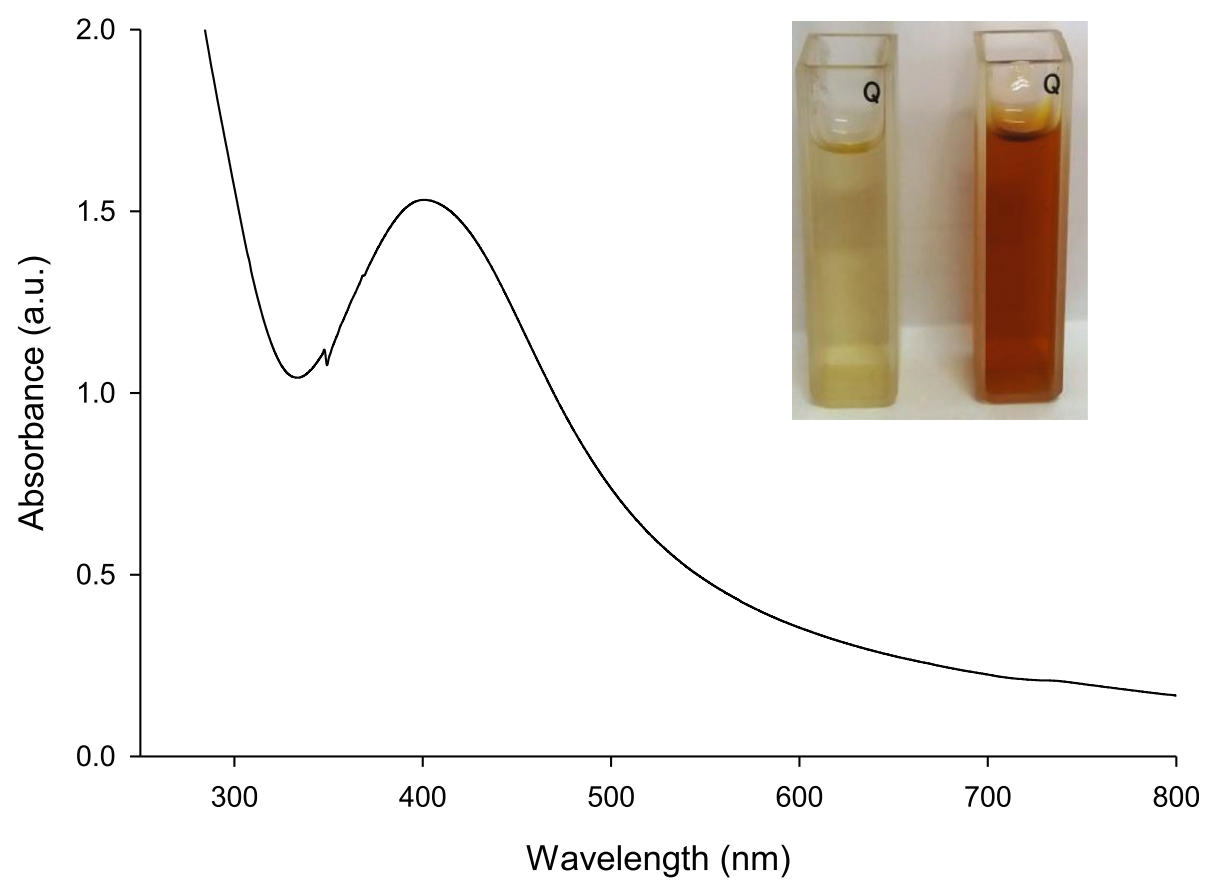

Fig. 1 UV-visible absorption spectrum of the biosynthesized AgNPs. The inset photo shows the change of reaction mixture color to reddish brown as a result of AgNP formation 

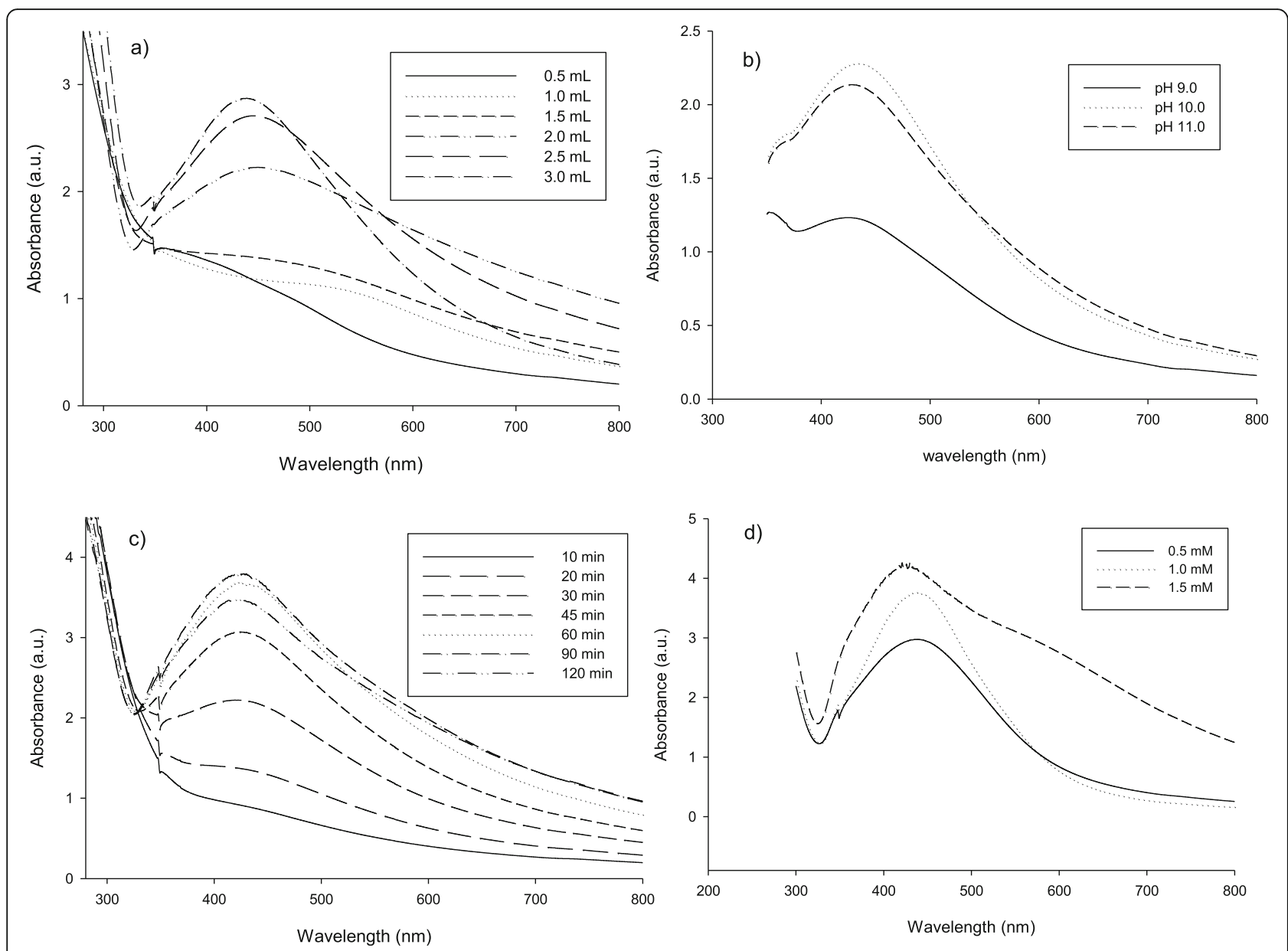

Fig. 2 UV-visible absorption spectra of AgNP biosynthesis optimization at different: a CFF volumes, $\mathbf{b}$ pH values, c reaction time, and $\mathbf{d}$ silver nitrate concentrations

formation of SPR peak and hence the possibility of activity recording.

\section{Effect of reaction time}

The effect of reaction time on AgNP formation was investigated by incubating the reaction mixtures under optimum conditions for different time intervals ranging between 10 and $120 \mathrm{~min}$. The obtained results indicated that the characteristic color intensity is directly proportional to the incubation time until 90 min which is the optimum time required for the maximum AgNP formation (Fig. 2c). After that, the increase in time course affected the formation process negatively as indicated in the peak of $120 \mathrm{~min}$ incubation time. Figure $2 \mathrm{c}$ also declares that the silver ion reduction velocity was slow for the first incubation durations (10-20 min) which were observed as small peaks at the region of activity (430 $\mathrm{nm})$. After that, an increase in peak intensity was recorded after longer time periods up to $90 \mathrm{~min}$ due to the increase in numbers of AgNPs, and then, the peak intensity starts to go down at $120 \mathrm{~min}$. Here, in the current case, $90 \mathrm{~min}$ is the optimum time for AgNP formation which is due to the exceptional reducing potential of the A. fumigatus DSM819 CFF active components.

\section{Effect of silver nitrate concentration}

The metal salt concentration has been revealed to influence nanoparticle biosynthesis effectively. The intensity of reaction color changed to reddish brown even at the lowest used concentration $(0.5 \mathrm{mM})$ and become more dark reddish brown at higher concentrations of silver nitrate $(1.0-1.5 \mathrm{mM})$. This developed color resulted to an increase in absorbance intensity up to $1.5 \mathrm{mM}$ of $\mathrm{AgNO}_{3}$, which is the highest obtained peak strength (Fig. 2d). It is worthy to mention that by using higher silver nitrate concentrations over $1.5 \mathrm{mM}$, a sudden black precipitate from silver nanoparticles occurred which impedes the formation of activity peak, and hence, no typical SPR band for AgNPs was obtained in the region of $410 \mathrm{~nm}$. 


\section{Characterization of the biosynthesized AgNPs SEM and EDAX profile of the biosynthesized AgNPs}

For the quantitative and qualitative evaluation of elements implicated in the process of nanoparticle formation, energy dispersive X-ray (EDAX) investigation usually applied. The profile obtained from SEM micrograph of the biosynthesized AgNPs by A. fumigatus DSM819 CFF at $\times 8000$ magnification shows the homogeneity of the prepared sample (Fig. 3c). The resulted EDAX analysis established the incidence of elemental silver as strong signal energy peaks around $3.0 \mathrm{keV}$, verifying the AgNP biosynthesis successfully. In addition, (EDAX) profile of the biosynthesized sample indicates the presence of silver by 89.72 , carbon 6.56 , and chloride 3.72 (weight \%), as well as EDAX mapping micrograph also confirming AgNP percentage in the biosynthesized sample as turquoise dots in the total sample black background (Fig. 3a, b).

\section{TEM and DLS analyses}

The obtained TEM profile reveals the spherical shape of the biosynthesized AgNPs as a result of treating silver nitrate solution by $A$. fumigatus DSM819 CFF. In addition, TEM profile shows the variation of the diameter range of the biosynthesized AgNPs between 10 and $34 \mathrm{~nm}$ (Fig. 4a). The obtained pictures show some individual silver particles in addition to some aggregates with dissimilar size ranges in indirect contact to ensure the nanoparticle stabilization by a capping agent. In order to get more precise view of particle size distribution, DLS technique was applied (Fig. 4b). Results obtained from DLS graph show that the biosynthesized AgNPs are in the nanoscale form with mean diameter of $46.2 \mathrm{~nm}$ and percentage of distribution as follows: $25 \%$ of distribution below than $30.6 \mathrm{~nm}$, $50 \%$ of distribution below than $46.2 \mathrm{~nm}, 75 \%$ of distribution below than $62.2 \mathrm{~nm}$, and $90 \%$ of distribution below than $84.4 \mathrm{~nm}$.

\section{FTIR spectroscopy}

In order to recognize the chief functional groups accountable for the formation of AgNPs by A. fumigatus DSM819 CFF and have a role in its capping and stabilization, FTIR spectroscopic analysis was conducted. The obtained FTIR spectrum is illustrated in Fig. 5, which declares the appearance of several absorption peaks. In this regard, the appearance of the sharp peak at $3431 \mathrm{~cm}^{-1}$ is thought to be overlapping $-\mathrm{NH}$ stretching vibration which is a typical phenomenon for proteins. In addition, $\mathrm{O}-\mathrm{H}$ stretching in flavonoids, alcohols, and phenolic compounds could be detected, and $\mathrm{C}-\mathrm{H}$ stretching vibrations of methylene, methyl, and methoxy groups could be observed at 2923 and $2856 \mathrm{~cm}^{-1}$. The $\mathrm{N}-\mathrm{C}=\mathrm{O}$ amide bond of proteins due to carbonyl stretch in proteins was recorded at $1626 \mathrm{~cm}^{-1}$, while absorption peaks at 1121 and $1024 \mathrm{~cm}^{-1}$ can be due to stretching vibration of $\mathrm{C}-\mathrm{N}$ aromatic and aliphatic amines.

\section{Antimicrobial activity}

The biosynthesized AgNPs through the mediation by $A$. fumigatus DSM819 CFF at different $\mathrm{pH}$ values exerted an antimicrobial activity against the studied representative pathogenic microorganisms (E. coli, B. mycoides, and $C$. albicans) which depends on the microbe type

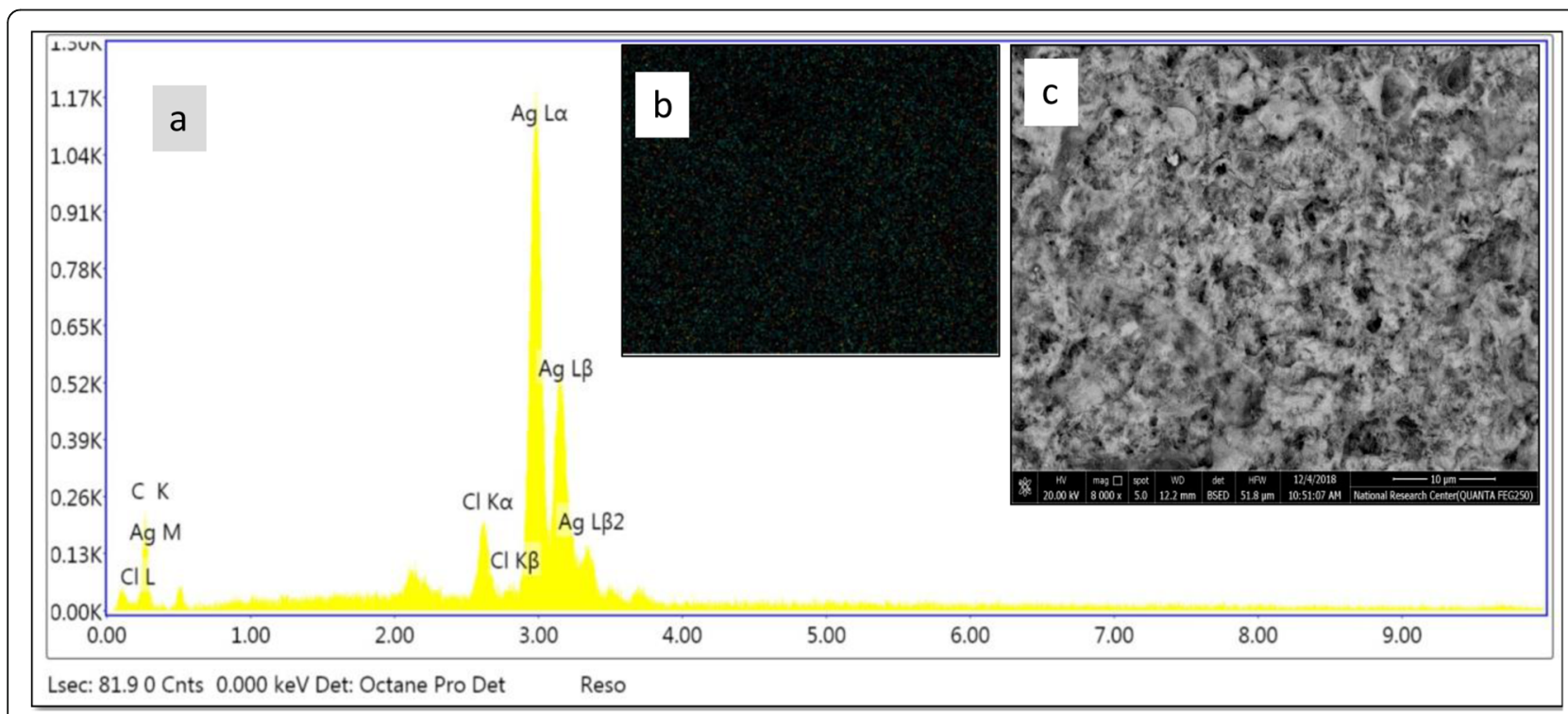

Fig. 3 Profiles of the biosynthesized AgNPs by A. fumigatus DSM819 CFF. a EDAX profile of nanosilver and other combined metals. b Magnified SEM micrograph (× 8000). c EDAX mapping micrograph showing AgNP percentage as turquoise $(\square)$ dots in the total sample black background. Samples used were produced from reaction mixture containing 60\% from A. fumigatus CFF and $1.5 \mathrm{mM} \mathrm{AgNO}_{3}$ and incubated for 90 min at $\mathrm{pH} 10$ 

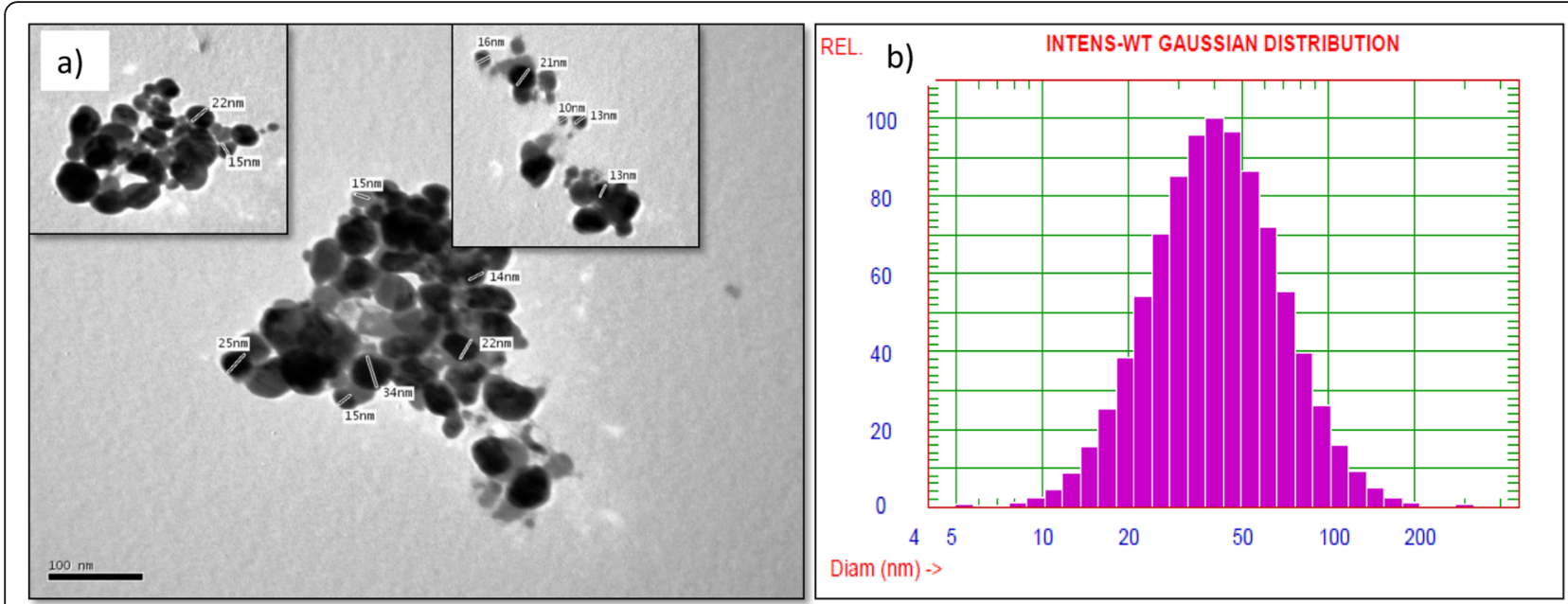

Fig. 4 a TEM micrograph using JEOL (JEM-1230) Electron Microscope (150Kx). b Dynamic light scattering (DLS) of the biosynthesized AgNPs through the mediation by A. fumigatus DSM819 CFF

and its cellular constituents. The exerted antimicrobial effect was measured as inhibition zone diameters $(\mathrm{mm})$, where the effect against Gram-negative bacteria ( $E$. coli) was the lowest one $(15-16 \mathrm{~mm})$ in comparison with Gram-positive bacteria (B. mycoides) which may owe to the dissimilarity in composition of the cell wall. In this regard, CFF as a control did not demonstrate any antimicrobial activity (Table 1 and Fig. 6). The antimicrobial activity in opposition to Candida albicans as pathogenic yeast was considerable and shows inhibition zone within the range against Gram-negative bacteria (Table 1 and Fig. 6).

\section{Antitumor activity of AgNPs}

In vitro cytotoxicity of the biosynthesized AgNPs was evaluated against BJ1 (normal skin fibroblast), and its antitumor activity was assessed against HCT116 (human colon carcinoma), A549 (lung carcinoma cell line), MCF7 (human Caucasian breast adenocarcinoma), and PC3 (prostate cell line) at different concentrations (0.4 to $54 \mu \mathrm{g} / \mathrm{ml}$ ) using MTT assay (Table 2). The results revealed that there was a straight dose-response association with tested cells at tested concentrations. In relation to cell fatality, lethal concentration of the

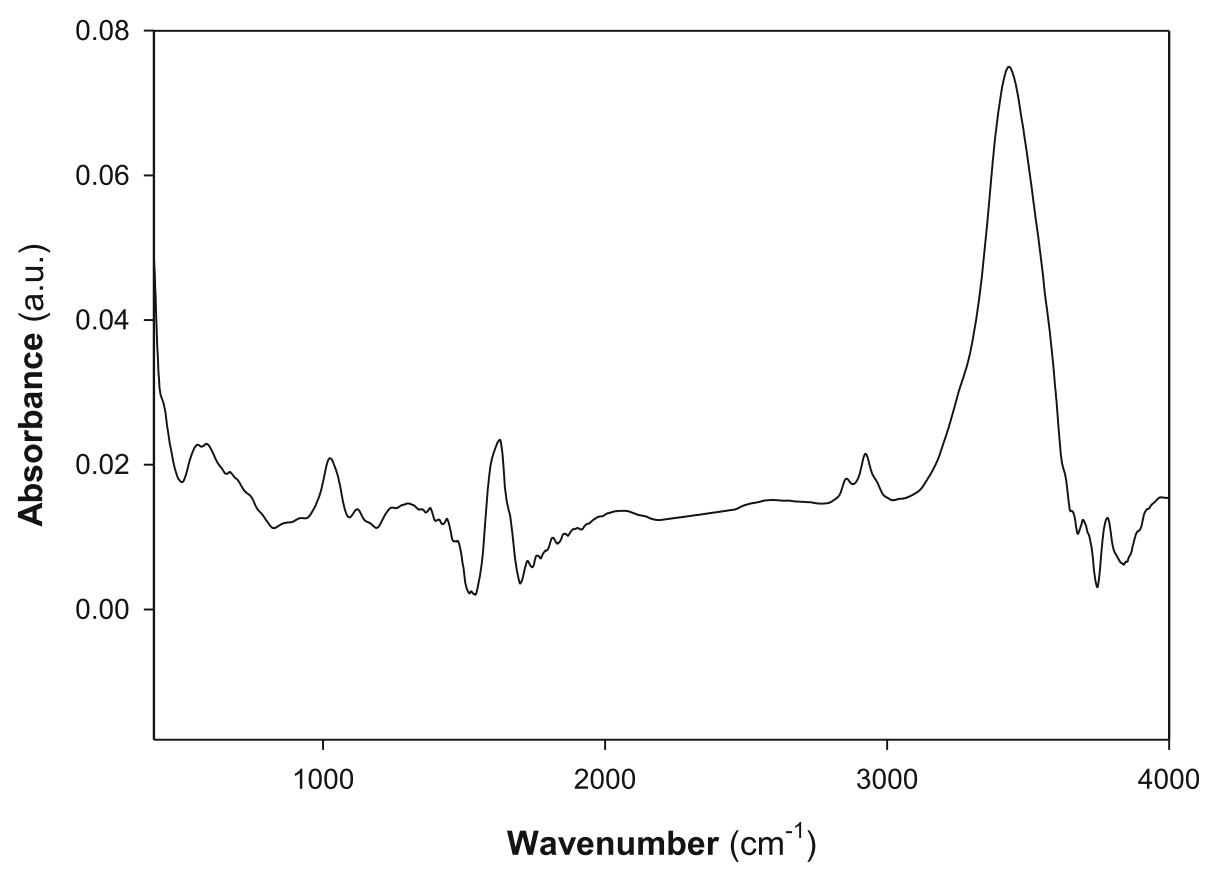

Fig. 5 FTIR spectroscopic analysis of the biosynthesized AgNPs through the mediation by A. fumigatus DSM819 CFF 
Table 1 Antimicrobial activity of the AgNPs biosynthesized by means of A. fumigatus CFF mediation

\begin{tabular}{llll}
\hline Sample & \multicolumn{3}{l}{ Diameter of inhibition zones $(\mathrm{mm})$} \\
\cline { 2 - 4 } & E. coli & B. mycoides & C. albicans \\
\hline Cell-free filtrate & 0 & 0 & 0 \\
$\mathrm{pH} 6.0$ & 16 & 18 & 17 \\
$\mathrm{pH} 8.0$ & 16 & 18 & 18 \\
$\mathrm{pH} 10$ & 16 & 19 & 18 \\
$\mathrm{pH} 12$ & 15 & 16 & 15 \\
\hline
\end{tabular}

biosynthesized AgNPs which causes the death of $50 \%$ of cells in $48 \mathrm{~h}\left(\mathrm{IC}_{50}\right)$ was found to be 31.1, 45.4, 40.9, and $33.5 \mu \mathrm{g} / \mathrm{ml}$ for HCT116, A549, MCF7, and PC3, respectively. In addition, $\mathrm{IC}_{90}$ was recorded to be $52.3,72.8$, 65.7 , and $60.7 \mu \mathrm{g} / \mathrm{ml}$ for the previously mentioned cell lines, respectively. The biosynthesized AgNPs were able to restrain the cell line growth at low concentrations, where at a concentration of $54 \mu \mathrm{g} / \mathrm{ml}$, they were able to inhibit 84.6, 60.8, 68.9, and $69.5 \%$ of HCT116, A549, MCF7, and PC3, respectively.

\section{Characterization of PET/C textile fabrics treated with biosynthesized AgNPs \\ FTIR analysis}

The FTIR spectrum (Fig. 7) of untreated PET/C blend fabric shows absorption bands at 1649-1712, 34083388 , and $2317 \mathrm{~cm}^{-1}$ which are typical to those of > $\mathrm{C}=$ $\mathrm{O}, \mathrm{O}-\mathrm{H}$, and $\mathrm{C}-\mathrm{H}$ stretching, respectively. New bands at 430,440 , and $460 \mathrm{~cm}^{-1}$ are observed in the spectrum of treated PET/C blend fabrics by AgNPs which can correspond to $\mathrm{Ag}-\mathrm{O}$ bonds. During this study, we found that only activated surfaces were able to fix AgNPs from dispersion solutions.

\section{SEM and EDAX analysis}

The SEM and EDAX analysis micrographs of untreated and treated $\mathrm{PET} / \mathrm{C}$ fabrics through immersion in $A$. fumigatus CFF and biosynthesized AgNPs solution are exposed in Fig. 8. As a quantitative and qualitative evaluation of elements found in untreated and treated fabrics, EDAX analysis was conducted (Fig. 8(a)). The resulted EDAX analysis established the incidence of elemental silver as weak energy peaks around $3.0 \mathrm{keV}$, verifying the adhesion of AgNPs successfully (Fig. 8(3b)), whereas there is no any detection of AgNPs in both untreated and control samples (Fig. 8(1a, 2a)). In addition, (EDAX) profile of the treated fabrics indicates the presence of silver by $0.25 \%$ (weight \%) on the PET/C fabrics after five washing cycles. The SEM images in Fig. 8(b) display the differences in textures of fabrics before and after treatments, where the smooth structure appears in Fig. 8(1b), whereas the cotton fabrics after coating with A. fumigatus CFF show proteinaceous agglomerations on its

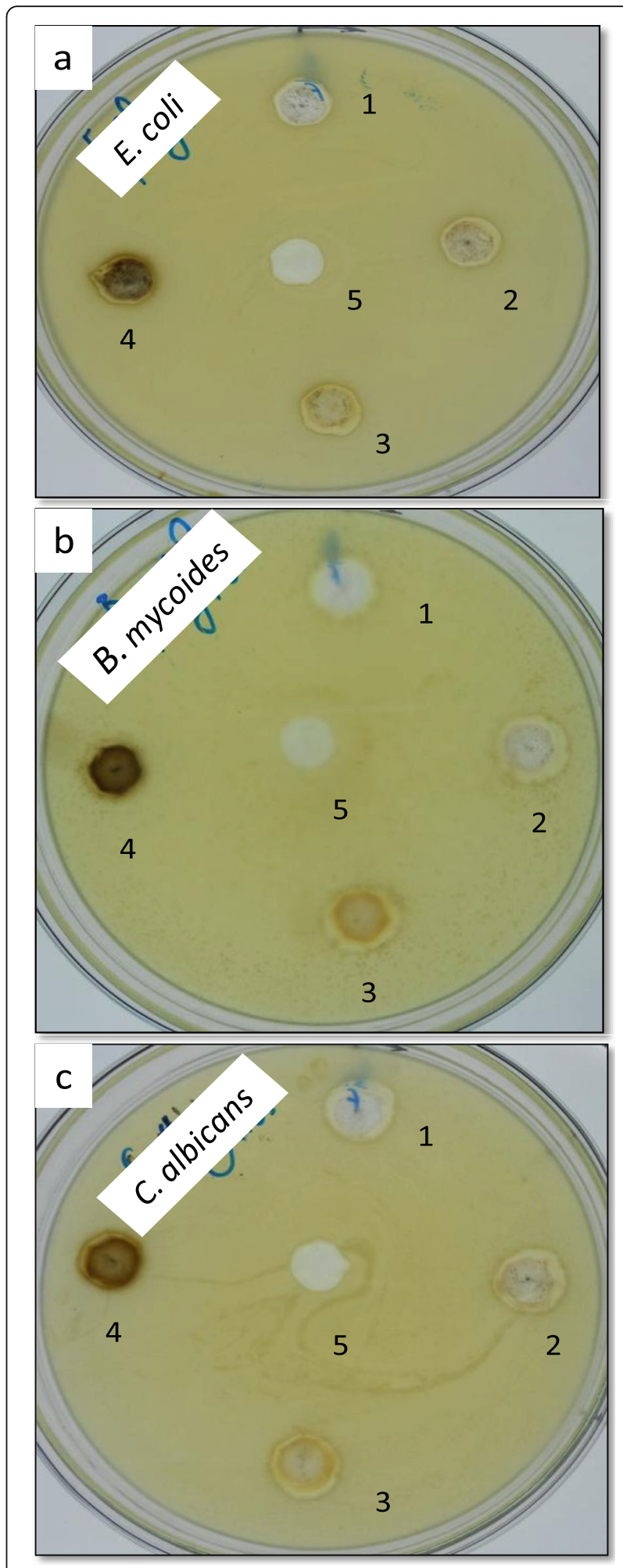

Fig. 6 Antimicrobial activity of the AgNPs biosynthesized by means of A. fumigatus CFF mediation. (1) AgNPs sample formed at pH 6.0, (2) at pH 8.0, (3) at pH 10.0, (4) at pH 12.0, and (5) cell free filtrate 
Table 2 Antitumor activity of the biosynthesized AgNPs

\begin{tabular}{|c|c|c|c|}
\hline \multirow[t]{2}{*}{ Cell line } & \multicolumn{3}{|c|}{ Antitumor activity } \\
\hline & $\mathrm{IC}_{50}(\mu \mathrm{g} / \mathrm{ml})$ & $\mathrm{IC}_{90}(\mu \mathrm{g} / \mathrm{ml})$ & Inhibition (\%) at 54 ppm \\
\hline BJ1 (normal skin fibroblast) & - & - & 15.6 \\
\hline HCT116 (colon cell line) & 31.1 & 52.3 & 84.6 \\
\hline A549 (lung carcinoma cell line) & 45.4 & 72.8 & 60.8 \\
\hline MCF7 (human Caucasian breast adenocarcinoma) & 40.9 & 65.7 & 68.9 \\
\hline PC3 (prostate cell line) & 33.5 & 60.7 & 69.5 \\
\hline
\end{tabular}

$I C_{50}$ lethal concentration of the sample which causes the death of $50 \%$ of cells in $48 \mathrm{~h}, I_{90}$ lethal concentration of the sample which causes the death of $90 \%$ of cells in $48 \mathrm{~h}$

surface Fig. 8(2b). After padding, the depositions of AgNPs on the fabrics are exposed in Fig. $8(3 \mathrm{~b})$ as a thinner uniform surface layer.

\section{Antimicrobial analysis}

It is evident from EDAX profile of the treated PET/C fabrics by AgNPs that the presence of silver is $0.25 \%$ (weight \%) on the PET/C fabrics. Even with this very low concentration, the treated fabrics exerted an antimicrobial activity against the tested microorganisms to give inhibition zone diameter of 15,15 , and $16 \mathrm{~mm}$ for $E$. coli, B. mycoides, and C. albicans, respectively.

\section{Discussion}

Typically, AgNPs demonstrate distinctive optical properties due to their distinguishing optical resonance identified as surface plasmon resonance (SPR), which happens as an outcome of nanoparticle size and shape [4]. The
UV-visible spectroscopy results using $A$. fumigatus DSM819 filtrate indicate the ability of $A$. fumigatus DSM819 to form AgNPs extracellulary through reduction of $\mathrm{Ag}^{+}$to form the AgNPs. The distinct and typical SPR band for AgNPs was obtained in the region of 410 nm [23]. The ability of $A$. fumigatus DSM819 to form AgNPs is directly proportional to CFF ratio in the reaction mixture, where Othman et al. [23] referred that due to the increase of biomolecules participating in the metal reduction process to result in nanoparticles biosynthesis. It is worthy to mention that the capability of the produced enzyme and protein as reducing and stabilizing agents appeared in alkaline medium, and when the reaction was performed at $\mathrm{pH}$ values lower than 9.0, no SPR peak was obtained. Usually, the time necessary for complete metal ion reduction through the fungal biosynthesis of metal nanoparticles can vary from 24 to $124 \mathrm{~h}$ [11]. Here, in the current case, $90 \mathrm{~min}$ is the optimum

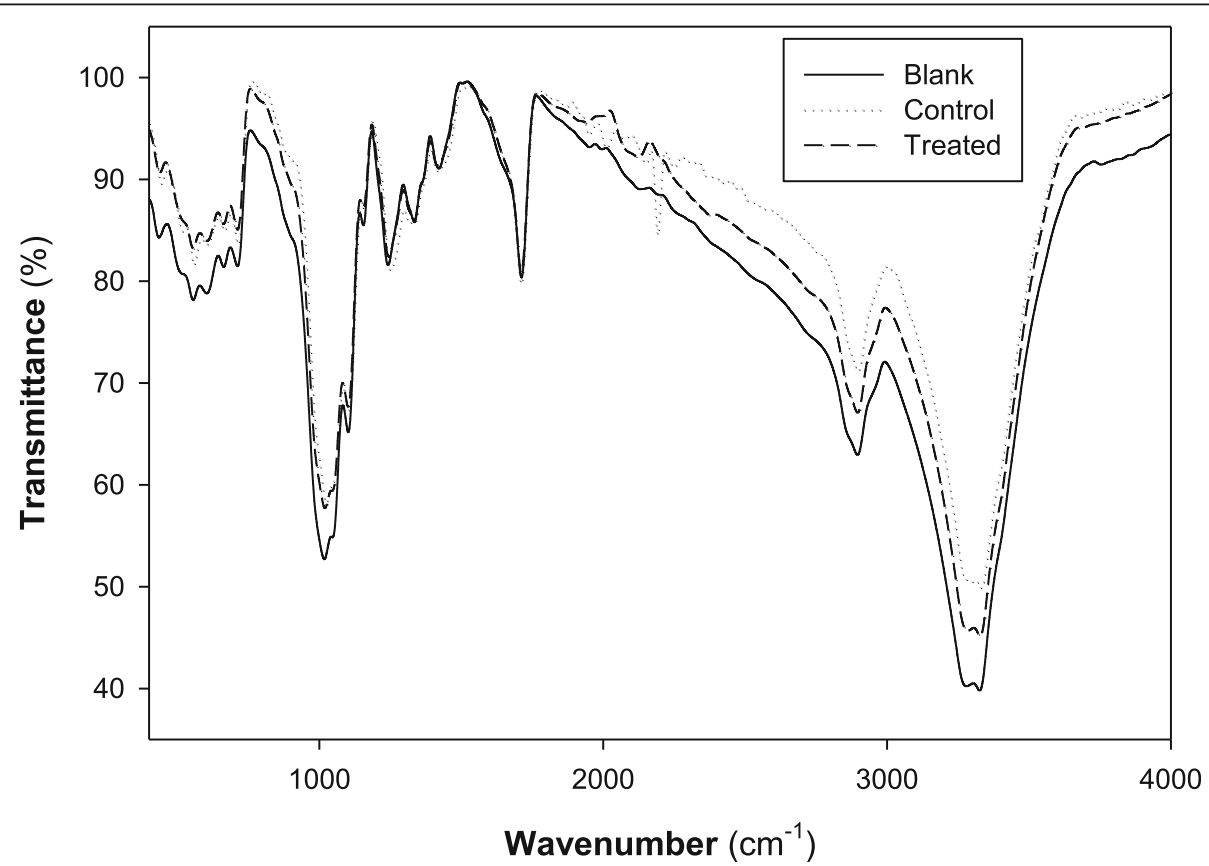

Fig. 7 FTIR spectroscopy of the textiles treated with biosynthesized AgNPs. PET/C hydrolyzed by cellulase (Blank), PET/C hydrolyzed by cellulase and then treated by A. fumigatus CFF (Control), and PET/C hydrolyzed by cellulase, then treated by A. fumigatus biosynthesized AgNPs (Treated) 


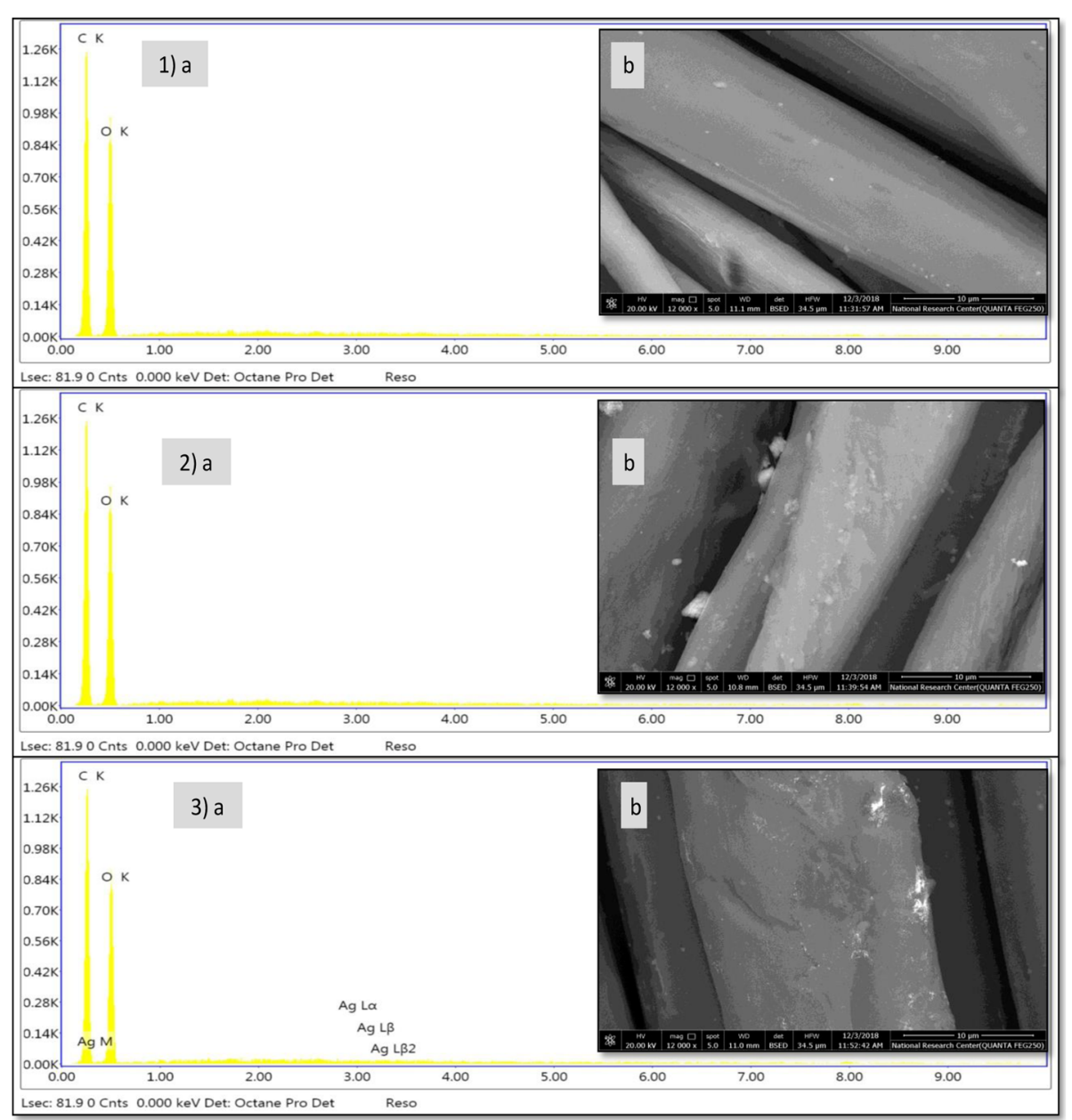

Fig. 8 EDAX analysis (a) and SEM micrographs (b) of the PET/C textile treated with AgNPs biosynthesized by means of A. fumigatus CFF mediation. 1, Blank PET/C (not treated); 2, PET/C Control (treated with CFF); and 3, treated with biosynthesized nanosilver

time for AgNP formation which is due to the exceptional reducing potential of the A. fumigatus DSM819 CFF active components. The metal salt concentration has been revealed to influence nanoparticle biosynthesis effectively [28]. In the current case, the intensity of reaction color changed to reddish brown even at the lowest used concentration $(0.5 \mathrm{mM})$ and become more dark reddish brown at higher concentrations of silver nitrate (1.0-1.5 mM). El-Rafie et al. [6] stated that by increasing silver nitrate concentration to high extent, the proteins and especially enzymes that present in the reaction mixture could be not sufficient for performing silver ion reduction to AgNPs and to stabilize them.

The highest counts of metallic silver nanocrystals typically appear at $3 \mathrm{keV}$ in EDAX analysis as a result of their surface plasmon resonance [5], which agrees with the resulted EDAX analysis that established the incidence of elemental silver as strong signal energy peaks around 3.0 $\mathrm{keV}$, and verifying the AgNPs biosynthesis successfully. The obtained TEM profile shows some individual silver particles in addition to some aggregates with dissimilar size ranges in indirect contact to ensure the nanoparticle stabilization by a capping agent $[5,23]$, with $90 \%$ of distribution below than $84.4 \mathrm{~nm}$ as obtained from DLS graph that confirm its nanoscale size. The FTIR spectrum declares the appearance of sharp peak at $3431 \mathrm{~cm}^{-1}$ that is thought to be overlapping $-\mathrm{NH}$ stretching vibration which is a typical phenomenon for proteins [16]. In addition, $\mathrm{O}-\mathrm{H}$ stretching in flavonoids, alcohols, and phenolic compounds (3781, 3694 , and $3431 \mathrm{~cm}^{-1}$ ) could be detected [17], and $\mathrm{C}-\mathrm{H}$ stretching vibrations of methylene, methyl, and methoxy groups could be observed at 2923 and $2856 \mathrm{~cm}^{-1}$. The $\mathrm{N}-$ $\mathrm{C}=\mathrm{O}$ amide bond of proteins due to carbonyl stretch in proteins was recorded at $1626 \mathrm{~cm}^{-1}$, while absorption peaks at 1121 and $1024 \mathrm{~cm}^{-1}$ can be due to stretching vibration of $\mathrm{C}-\mathrm{N}$ aromatic and aliphatic amines [23].

The biosynthesized AgNPs have several featured applications like biomedical applications and antimicrobial surfaces due to its unique features and biocompatibility. The biosynthesized AgNPs through the mediation by $A$. 
fumigatus DSM819 CFF exerted an antimicrobial activity against the studied representative pathogenic microorganisms (E. coli, B. mycoides, and C. albicans) which depends on the microbe type and its cellular constituents [30]. Diverse routes of action can be used to understand the antimicrobial activity of AgNPs toward microorganisms. One of these mechanisms is AgNPs could attach to the negative charge on microbial cell surface which alter the cell wall and cell membrane properties, hence affecting osmoregulation, permeability, respiration, and electron transport [15]. As another approach, AgNPs can interact with cell constituents including DNA and proteins after penetrating microbial cell wall [2]. In addition, silver ions released by silver nanoparticles reason a bigger biocidal consequence depending on their dose and size [13, 24].

The results from in vitro cytotoxicity of the biosynthesized AgNPs revealed that there was a straight dose-response association with tested cells at tested concentrations. The biosynthesized AgNPs were able to restrain the cell line growth at low concentrations, where at a concentration of $54 \mu \mathrm{g} / \mathrm{ml}$, they were able to inhibit 84.6, 60.8, 68.9, and $69.5 \%$ of HCT116, A549, MCF7, and PC3, respectively. Anand et al. [1] reported that a concentration close to $500 \mathrm{mg} / \mathrm{ml}$ of AgNPs biosynthesized by marine sediment significantly inhibits the HEp2 cell line growth by more than $85 \%$. In this regard, some in vitro studies exposed the translocation of AgNPs in tumor cell line with a LC50 of $300 \mathrm{mg} / \mathrm{ml}$ [32]. Jacob et al. [9] stated that AgNPs could stimulate reactive oxygen groups and cause destruction to cellular components leading to cell fatality.

Evidently, enzymatic hydrolysis of PET/C blend fabrics before treatment with AgNPs induced a significant change in the chemical composition of the PET/C blend fabric surfaces. New bands at 430,440 , and $460 \mathrm{~cm}^{-1}$ are observed in the FTIR spectrum of treated PET/C blend fabrics by AgNPs which can correspond to Ag-O bonds. The presence of these bands can support the ionic character of the new band formed due the addition of AgNPs to activated fabrics with cellulase. During this study, we found that only activated surfaces were able to fix AgNPs from dispersion solutions. The resulted EDAX analysis of PET/C blend fabrics treated with AgNPs established the incidence of elemental silver as weak energy peaks around $3.0 \mathrm{keV}$, verifying the adhesion of AgNPs successfully. In addition, (EDAX) profile of the treated fabrics indicates the presence of silver by $0.25 \%$ (weight \%) on the PET/C fabrics after five washing cycles. The SEM images display the differences in textures of fabrics before and after treatments, where the smooth structure appears in cellulase-treated sample, whereas the cotton fabrics after coating with A. fumigatus CFF show proteinaceous agglomerations on its surface, and the depositions of AgNPs on the fabrics as a thinner uniform surface layer after padding could be detected. Even with the detected very low concentration of nanosilver, the treated fabrics exerted an antimicrobial activity against E. coli, B. mycoides, and C. albicans. In this regard, El-Rafie et al. [6] reported that a diluted solution from Fusarium solani biosynthesized AgNPs imparts antibacterial activity to the cotton fabrics against both Gram-negative (Escherichia coli) and Gram-positive (Staphylococcus aureus) bacteria due to AgNP deposition onto cellulose molecules of cotton fabric and then via physical and chemical bonding.

\section{Conclusions}

An efficient eco-friendly and inexpensive process for green synthesis of silver nanoparticles (AgNPs) through the fungal mediation of Aspergillus fumigatus DSM819 was achieved. AgNP biosynthesis using A. fumigatus DSM819 cell-free filtrate (CFF) was studied throughout investigating the most factors affecting the synthesis process. Under the optimum conditions, the biosynthesized AgNPs were of spherical shape with $90 \%$ of distribution below than $84.4 \mathrm{~nm}$. The biosynthesized AgNPs exerted both antimicrobial and antitumor activities against the studied representative pathogenic microorganisms (E. coli, B. mycoides, and $C$. albicans) and in vitro human tumor cell lines. The treated PET/C fabrics by the biosynthesized AgNPs also exerted an antimicrobial activity. This green biosynthesis method is a non-toxic alternative to the traditional chemical and physical methods, and would be appropriate for biological large-scale production and prospective treatments.

\section{Abbreviations \\ A549: Lung carcinoma cell line; AgNPs: Silver nanoparticles; BJ1: Normal skin fibroblast; CFF: Cell-free filtrate; DLS: Dynamic light scattering; DMSO: Dimethyl sulfoxide; EDAX: Energy dispersive X-ray; FTIR: Fourier transform infrared; HCT116: Colon cell line; $I_{50}$ : Lethal concentration which causes the death of $50 \%$ of cells; $\mid C_{90}$ : Lethal concentration which causes the death of $90 \%$ of cells; MCF7: Caucasian breast adenocarcinoma; MTT: 3-(4,5- Dimethylthiazol-2-yl)-2,5-diphenyl tetrazolium bromide; PC3: Prostate cell line; PET/C: Polyester/cotton blend; SEM: Scanning electron microscope; SPR: Surface plasmon resonance; TEM: Transmitting electron microscopic}

\section{Acknowledgements}

Not applicable.

\begin{abstract}
Authors' contributions
$\mathrm{AMO}$ and MAE planned and performed the practical work concerning the green synthesis and antimicrobial activity of AgNPs and its characterization and helped in analyzing and interpreting the obtained data. NGA treated the textile fabrics with the produced AgNPs and did the fabric characterization. $\mathrm{MMH}$ and AME analyzed and interpreted the obtained data especially the part of biological activities. AME supervised the whole study through the project AR111103 and shared in the manuscript writing. AMO was a major contributor in the writing of the manuscript. All authors read and approved the final manuscript.
\end{abstract}

\section{Funding}

The current study was financially supported by the National Research Centre (Dokki, Giza, 12622, Egypt) through the research project number AR111103, 
which finance all instrumental analysis and electronic imaging in the course of this work.

\section{Availability of data and materials}

The datasets used and/or analyzed during the current study are available from the corresponding author on reasonable request.

\section{Ethics approval and consent to participate}

Not applicable

\section{Consent for publication}

Not applicable

\section{Competing interests}

The authors declare that they have no competing interests.

\section{Author details}

${ }^{1}$ Microbial Chemistry Department, Genetic Engineering and Biotechnology Research Division, National Research Centre, 33 El Bohouth St., Dokki, Giza 12622, Egypt. ${ }^{2}$ Protein and Manmade Fibers Department, Textile Research Division, National Research Centre, 33 El Bohouth St., Dokki, Giza 12622, Egypt.

\section{Received: 30 July 2019 Accepted: 23 September 2019}

\section{Published online: 01 November 2019}

\section{References}

1. Anand BG, Thomas CKN, Prakash S, Kumar CS (2015) Biosynthesis of silver nano-particles by marine sediment fungi for a dose dependent cytotoxicity against HEp2 cell lines. Biocatalysis Agric Biotechnol 4:150-157. https://doi. org/10.1016/j.bcab.2015.01.002

2. AshaRani PV, Low Kah Mun G, Hande MP, Valiyaveettil S (2009) Cytotoxicity and genotoxicity of silver nanoparticles in human cells. ACS Nano 3:279290. https://doi.org/10.1021/nn800596w

3. Behravan M, Hossein Panahi A, Naghizadeh A, Ziaee M, Mahdavi R, Mirzapour A (2019) Facile green synthesis of silver nanoparticles using Berberis vulgaris leaf and root aqueous extract and its antibacterial activity. Int J Biol Macromol 124:148-154. https://doi.org/10.1016/j.ijbiomac.2018.11.101

4. Bindhu MR, Umadevi M (2013) Green synthesized gold nanoparticles as a probe for the detection of $\mathrm{Fe}^{3+}$ ions in water. J Clust Sci 25:969-978. https://doi.org/10.1007/s10876-013-0679-8

5. Devi LS, Joshi SR (2015) Ultrastructures of silver nanoparticles biosynthesized using endophytic fungi. J Microsc Ultrastruct 3:29-37. https://doi.org/10. 1016/j.jmau.2014.10.004

6. El-Rafie MH, Shaheen TI, Mohamed AA, Hebeish A (2012) Bio-synthesis and applications of silver nanoparticles onto cotton fabrics. Carbohydr Polym 90: 915-920. https://doi.org/10.1016/j.carbpol.2012.06.020

7. Elsayed MA, Othman AM, Hassan MM, Elshafei AM (2018) Optimization of silver nanoparticles biosynthesis mediated by Aspergillus niger NRC1731 through application of statistical methods: enhancement and characterization. 3 Biotech 8. https://doi.org/10.1007/s13205-018-1158-6

8. Elumalai EK, Kayalvizhi K, Silvan S (2014) Coconut water assisted green synthesis of silver nanoparticles. J Pharm Bioallied Sci 6:241-245. https://doi. org/10.4103/0975-7406.142953

9. Jacob SJP, Finub JS, Narayanan A (2012) Synthesis of silver nanoparticles using Piper longum leaf extracts and its cytotoxic activity against Hep-2 cell line. Colloids Surf B: Biointerfaces 91:212-214. https://doi.org/10.1016/j. colsurfb.2011.11.001

10. Kathiresan K, Manivannan S, Nabeel MA, Dhivya B (2009) Studies on silver nanoparticles synthesized by a marine fungus, Penicillium fellutanum isolated from coastal mangrove sediment. Colloids Surf B: Biointerfaces 71: 133-137. https://doi.org/10.1016/j.colsurfb.2009.01.016

11. Korbekandi H, Iravani S, Abbasi S (2009) Production of nanoparticles using organisms. Crit Rev Biotechnol 29:279-306. https://doi.org/10.3109/ 07388550903062462

12. Lee K-J, Park S-H, Govarthanan M, Hwang P-H, Seo Y-S, Cho M, Lee W-H, Lee J-Y, Kamala-Kannan S, Oh B-T (2013) Synthesis of silver nanoparticles using cow milk and their antifungal activity against phytopathogens. Mater Lett 105:128-131. https://doi.org/10.1016/j.matlet.2013.04.076
13. Liu J, Sonshine DA, Shervani S, Hurt RH (2010) Controlled release of biologically active silver from nanosilver surfaces. ACS Nano 4:6903-6913. https://doi.org/10.1021/nn102272n

14. Lu R, Yang D, Cui D, Wang Z, Guo L (2012) Egg white-mediated green synthesis of silver nanoparticles with excellent biocompatibility and enhanced radiation effects on cancer cells. Int J Nanomedicine 7:2101-2107. https://doi.org/10.2147/IJN.S29762

15. Marambio-Jones C, Hoek EMV (2010) A review of the antibacterial effects of silver nanomaterials and potential implications for human health and the environment. J Nanopart Res 12:1531-1551. https://doi. org/10.1007/s11051-010-9900-y

16. Mishra P, Kumar Sahoo S, Kumar Naik G, Parida K (2015) Biomimetic synthesis, characterization and mechanism of formation of stable silver nanoparticles using Averrhoa carambola L. leaf extract. Mater Lett 160:566571. https://doi.org/10.1016/j.matlet.2015.08.048

17. Mittal AK, Bhaumik J, Kumar S, Banerjee UC (2014) Biosynthesis of silver nanoparticles: elucidation of prospective mechanism and therapeutic potential. J Colloid Interface Sci 415:39-47. https://doi.org/10.1016/j.jcis.2013.10.018

18. Mosmann T (1983) Rapid colorimetric assay for cellular growth and survival: application to proliferation and cytotoxicity assays. J Immunol Methods 65:55-63

19. Mukherjee P, Ahmad A, Mandal D, Senapati S, Sainkar SR, Khan MI, Parishcha R, Ajaykumar PV, Alam M, Kumar R, Sastry M (2001) Fungusmediated synthesis of silver nanoparticles and their immobilization in the mycelial matrix: a novel biological approach to nanoparticle synthesis. Nano Lett 1:515-519. https://doi.org/10.1021/nl0155274

20. Mukherjee P, Roy M, Mandal BP, Dey GK, Mukherjee PK, Ghatak J, Tyagi AK, Kale SP (2008) Green synthesis of highly stabilized nanocrystalline silver particles by a non-pathogenic and agriculturally important fungus $T$. asperellum. Nanotechnology 19:075103. https://doi.org/10.1088/0957-4484/ 19/7/075103

21. Netala VR, Bethu MS, Pushpalatha B, Baki VB, Aishwarya S, Rao JV, Tartte $V$ (2016) Biogenesis of silver nanoparticles using endophytic fungus Pestalotiopsis microspora and evaluation of their antioxidant and anticancer activities. Int J Nanomedicine 11:5683-5696. https://doi.org/ $10.2147 /$ IJN.S112857

22. Nowack B, Bucheli TD (2007) Occurrence, behavior and effects of nanoparticles in the environment. Environ Pollut 150:5-22. https://doi.org/ 10.1016/j.envpol.2007.06.006

23. Othman AM, Elsayed MA, Elshafei AM, Hassan MM (2016) Nano-silver biosynthesis using culture supernatant of Penicillium politans NRC510: optimization, characterization and its antimicrobial activity. Int J ChemTech Res 9:433-444

24. Othman AM, Elsayed MA, Elshafei AM, Hassan MM (2017) Application of response surface methodology to optimize the extracellular fungal mediated nanosilver green synthesis. J Genet Eng Biotechnol 15:497-504. https://doi.org/10.1016/j.jgeb.2017.08.003

25. Otunola GA, Afolayan AJ (2018) In vitro antibacterial, antioxidant and toxicity profile of silver nanoparticles green-synthesized and characterized from aqueous extract of a spice blend formulation. Biotechnol Biotechnol Equip 32:724-733. https://doi.org/10.1080/13102818.2018.1448301

26. Patil SR (2014) Antibacterial activity of silver nanoparticles synthesized from Fusarium semitectum and green extracts. Int J Sci Eng Res 2:140-145

27. Philip D (2010) Honey mediated green synthesis of silver nanoparticles. Spectrochim Acta A Mol Biomol Spectrosc 75:1078-1081. https://doi.org/10. 1016/j.saa.2009.12.058

28. Pimprikar PS, Joshi SS, Kumar AR, Zinjarde SS, Kulkarni SK (2009) Influence of biomass and gold salt concentration on nanoparticle synthesis by the tropical marine yeast Yarrowia lipolytica NCIM 3589. Colloids Surf B: Biointerfaces 74:309-316. https://doi.org/10.1016/j.colsurfb.2009.07.040

29. Sharma VK, Yngard RA, Lin Y (2009) Silver nanoparticles: green synthesis and their antimicrobial activities. Adv Colloid Interf Sci 145:83-96. https://doi. org/10.1016/j.cis.2008.09.002

30. Shrivastava S, Bera T, Roy A, Singh G, Ramachandrarao P, Dash D (2007) Characterization of enhanced antibacterial effects of novel silver nanoparticles. Nanotechnology 18:225103. https://doi.org/10.1088/0957$4484 / 18 / 22 / 225103$

31. Siddiqui MH, Al-Whaibi MH, Firoz M, Al-Khaishany MY (2015) Role of nanoparticles in plants. In: Siddiqui MH, Al-Whaibi MH, Mohammad F (eds) Nanotechnology and plant sciences: nanoparticles and their impact on plants. Springer International Publishing, Cham, pp 19-35 
32. Sriram MI, Kanth SBM, Kalishwaralal K, Gurunathan S (2010) Antitumor activity of silver nanoparticles in Dalton's lymphoma ascites tumor model. Int J Nanomedicine 5:753-762. https://doi.org/10.2147/JJN.S11727

33. Zhang X, Yan S, Tyagi RD, Surampalli RY (2011) Synthesis of nanoparticles by microorganisms and their application in enhancing microbiological reaction rates. Chemosphere 82:489-494. https://doi.org/10.1016/j. chemosphere.2010.10.023

\section{Publisher's Note}

Springer Nature remains neutral with regard to jurisdictional claims in published maps and institutional affiliations.

Submit your manuscript to a SpringerOpen ${ }^{0}$ journal and benefit from:

- Convenient online submission

- Rigorous peer review

- Open access: articles freely available online

High visibility within the field

- Retaining the copyright to your article

Submit your next manuscript at $\boldsymbol{\wedge}$ springeropen.com 